\title{
Different Effects of BMP-2 on Marrow Stromal Cells from Human and Rat Bone
}

\author{
Anna M. Osyczka David L. Diefenderfer Geeta Bhargave Phoebe S. Leboy \\ Department of Biochemistry, School of Dental Medicine, University of Pennsylvania, Philadelphia, Pa., USA
}

\section{Key Words}

Osteogenesis · Bone morphogenetic proteins .

Transcription factors · Alkaline phosphatase .

Mesenchymal stem cells $\cdot$ Marrow stromal cells

\begin{abstract}
Bone morphogenetic proteins (BMPs) promote the differentiation of osteoprogenitor cells, and also induce osteogenesis in bone marrow stromal cells (MSC) from rats and mice. However, compared to results with animal models, BMPs are relatively inefficient in inducing human MSC to undergo osteogenesis, and are much less effective in promoting bone formation in human clinical trials. Previous studies indicated that, while human MSC respond to dexamethasone with elevated levels of the osteoblast marker alkaline phosphatase, most isolates of human MSC fail to show alkaline phosphatase induction in response to BMP-2, BMP-4, or BMP-7. Several other
\end{abstract}

\begin{tabular}{ll} 
Abbreviations used in this paper \\
\hline BMPs & bone morphogenetic proteins \\
CA & constitutively active \\
MSCs & marrow stromal cells
\end{tabular}

\section{KARGER}

(c) 2004 S. Karger AG, Basel

Fax +41613061234

E-Mail karger@karger.ch

www. karger.com
Accessible online at: www. karger.com/cto genes known to be induced by BMPs are appropriately regulated; thus, human MSC are capable of some BMPactivated signaling. Analysis of the BMP receptors ALK-3 and ALK- 6 indicated that, although ALK-6 mRNA was not expressed in human MSC, overexpressing a constitutively active ALK-6 receptor did not induce elevated alkaline phosphatase. Real-time RT-PCR was used to investigate expression of several osteoblast-related transcription factors in MSC after 6 days' exposure to BMP2 or dexamethasone. Msx-2, a transcription factor that has been reported to inhibit differentiation of osteoprogenitor cells, showed 10-fold elevation in BMP-2-treated human MSC, but not in BMP-2-treated rat MSC. Overexpression of Msx-2 in human and rat MSC, however, did not alter alkaline phosphatase levels, which suggests that absence of BMP-stimulated alkaline phosphatase was not caused by the BMP-2-induced increase in Msx-2. Although Runx2 isoforms have been implicated in control of osteoblast differentiation, levels of this transcription factor were unaffected by BMP treatment. Expression of the FKHR transcription factor, which has been reported to regulate alkaline phosphatase transcription in mouse cells, showed a modest increase in response to BMP-2, but a much greater increase in dexamethasonetreated cells. We propose that BMP regulation of the bone/liver/kidney alkaline phosphatase gene is indirect, requiring expression of new transcription factor(s) that behave differently in rodent and human MSC.

Copyright $\odot 2004$ S. Karger AG, Basel

Phoebe S. Leboy

Dental Biochemistry, University of Pennsylvania

240 S. 40th Street

Philadelphia, PA 19104-6030 (USA)

Tel. +1 215898 8933, Fax +1 215898 3695, E-Mail phoebe@biochem.dental.upenn.edu 


\section{Introduction}

Successful outcomes for fracture repair, alveolar ridge augmentation, maintenance of dental implants and craniofacial surgery require formation of new bone. Efficient bone formation in adults relies on the recruitment of osteoblast precursors to the site, followed by osteoblast maturation, matrix deposition and mineralization. The body does not possess a large population of such osteoblast precursors, but recruits adult stem cells having the ability to undergo differentiation upon demand. The existence of these cells was first demonstrated by Friedenstein et al. [1987] and Owen et al. [1987], who showed that the stromal component of bone marrow contains a population of fibroblastic cells (CFU-F). These CFU-F adhered to tissue culture plastic and formed both cartilage and bone when placed in diffusion chambers and implanted into animals [Friedenstein et al., 1987; Mardon et al., 1987]. When the same cells were placed in culture, they also displayed evidence of osteogenesis [Latzinik et al., 1987; Owen et al., 1987]. It is now recognized that the bone marrow stroma is a major reservoir of these mesenchymal stem cells, which can be induced to differentiate not only into osteoblasts and chondrocytes, but also adipocytes, neural cells and fibroblastic cells that support hematopoiesis [Grigoriadis et al., 1988; Aubin, 1998; Dennis et al., 1999; Kopen et al., 1999; Muraglia et al., 2000]. The population of mesenchymal stem cells within bone marrow is small (considerably less than $0.1 \%$ ), and varies with age and species. It is increasingly apparent that bone marrow is not the only site with stem cells capable of osteogenesis; such cells are also present in connective tissues far from sites of bone marrow as well as in umbilical cord blood and, at extremely low levels, in peripheral blood [Erices et al., 2000; Kuznetsov et al., 2001; Sen et al., 2001; Erickson et al., 2002; Romanov et al., 2003].

Whether these cells remain as multipotential stem cells or become committed to a particular differentiation pathway is apparently under the control of both systemic and local factors. One set of local factors, the bone morphogenetic proteins (BMPs), have attracted considerable interest as candidate therapies for promoting bone formation. Members of the TGF- $\beta$ superfamily of growth and differentiation factors, BMPs were originally identified by Urist [1965] as organic components found in bone matrix that could induce ectopic bone formation. BMPs, particularly BMP-2, BMP-4 and BMP-7 (OP-1), have been demonstrated to promote increased bone formation and bone repair in several animal models [Gerhart et al., 1993;
Cook et al., 1994; Ripamonti et al., 1996; Reddi, 1998; Wozney and Rosen, 1998; Heckman et al., 1999]. When added to cultures of committed osteoprogenitor cells, BMP-2, BMP-4, or BMP-7 will promote cell differentiation into osteoblasts. Similarly, when cultures of rat or mouse marrow stromal cells (MSC) are treated with BMPs, these cells will commit to the osteogenic or chondrogenic lineage and, depending on culture conditions, mature into either osteoblasts or chondrocytes.

A committed osteoprogenitor cell is often recognized by its ability to mature to a more differentiated phenotype in the presence of a permissive environment, i.e. its ability to produce bone matrix proteins and express the high levels of alkaline phosphatase that seem essential for mineralization of the bone matrix. With the 1997 discovery of the Runx2 (cbfa1) transcription factor that is expressed primarily in osteoblasts, and observations that absence of Runx2 prevented bone formation [Komori et al., 1997; Mundlos et al., 1997; Otto et al., 1997; Nakashima et al., 2002], it has been assumed that a committed osteoprogenitor should show elevated levels of Runx2. Consistent with this hypothesis, overexpression of Runx 2 in myogenic mouse $\mathrm{C} 2 \mathrm{C} 12$ cells induces an osteoblast phenotype and BMPs induce Runx 2 expression in $\mathrm{C} 2 \mathrm{C} 12$ cells [Lee et al., 2000].

While both BMP signaling and Runx 2 expression have been implicated in the expression of an osteoblast phenotype, the precise relationship between BMPs, Runx2 expression, and transcription of osteoblast-related genes remains to be defined. One possibility is that BMPinduced signaling activates the Run $x 2$ promoter to produce Runx 2 protein that, in turn, binds to and activates genes coding for osteoblast-specific proteins. BMP signaling is initiated by extracellular BMPs binding to heterodimeric BMP receptors, causing phosphorylation and activation of intracellular Smad signaling molecules. While the same type of mechanism is employed for TGF- $\beta$ signaling, specificity is accomplished by using different receptors and Smads for TGF- $\beta$ and BMPs [Massagué and Wotton, 2000; Miyazono et al., 2001]. It is plausible that activated BMP-regulated Smads (Smad1, 5 or 8) bind to the Runx2 promoter causing increased transcription. However, a 1.4-kb region upstream of the Runx 2 gene shows no response to BMP [Xiao et al., 2001] and osteoblast-specific activation of Runx2 appears dependent on an AP-1 site [Zambotti et al., 2002]. Another hypothesis is that Runx 2 and activated Smads work together to regulate transcription of some osteoblast-specific proteins. There is evidence that some genes are indeed regulated by a Runx2-Smad complex [Hanai et al., 1999; Alliston et al., 
2001; Leboy et al., 2001; Moustakas and Heldin, 2002]. However, while TGF- $\beta$ has been reported to repress expression of both Runx2 and osteocalcin via a SmadRunx 2 complex [Alliston et al., 2001], there is currently no evidence that any osteoblast-related genes are directly regulated by BMP-induced Smad binding to a regulatory region of these genes.

Among the well-studied proteins characteristic of osteoblasts, the osteopontin gene appears to be regulated by BMP-activated Smad binding to Hoxc-8 and removing this repressor from its DNA binding site [Yang et al., 2000]. The osteocalcin promoter is upregulated by binding of several transcription factors including Runx2, C/ EBP, the vitamin D receptor and AP-1 [Owen et al., 1990; McLarren et al., 2000; Gutierrez et al., 2002]. Bone sialoprotein transcription has been variously reported to be either repressed [Javed et al., 2001] or unaffected by Runx2 [Banerjee et al., 2001; Kiyoshima et al., 2002], and we currently have no information concerning transcription factors binding to and regulating the most commonly assayed osteoblast marker, alkaline phosphatase.

We have recently reported that, while BMP induces alkaline phosphatase expression in rat and mouse MSC, it usually fails to do so with human MSC [Diefenderfer et al., 2003b]. Rat MSC will differentiate into osteoblasts by treatment with either BMPs or dexamethasone [Rickard et al., 1994; Hanada et al., 1997], and mouse MSC undergo osteogenesis with BMPs but not dexamethasone [Balk et al., 1997; Abe et al., 2000; Diefenderfer et al., 2003b]. Our studies with human MSC derived from 17 individuals showed that all samples cultured with $100 \mathrm{n} M$ dexamethasone responded with elevated levels of alkaline phosphatase mRNA and activity, but only one showed a comparable alkaline phosphatase induction when treated with either BMP-2, BMP-4, or BMP-7 [Diefenderfer et al., 2003b]. If human MSC were exposed to dexamethasone during initial culture, approximately half of first passage human MSC samples showed an elevated alkaline phosphatase level in the presence of BMPs. RT-PCR analysis of RNA from human MSC cultured with BMP indicated that BMPs were capable of autoregulating BMP-2 expression, inducing the BMP binding protein noggin, and, at later stages, inducing expression of the osteoblastrelated gene, bone sialoprotein [Diefenderfer et al., 2003a, b]. This indicated that human MSC were capable of some BMP responses.

The studies reported here investigate human MSC expression of BMP receptors and transcription factors that might be implicated as downstream modulators of BMP signaling.

BMP Effects on Marrow Stromal Cell

Osteogenesis

\section{Materials and Methods}

\section{Isolation and Culture of MSCs}

Human marrow cells were aspirated from the medullary cavities of femurs, and rat marrow cells extruded from femurs of 4- to 5week-old rats as described previously [Diefenderfer et al., 2003b]. No detailed medical history of the patients was sought, and the only characteristics identifying each human sample were date of surgery, age and gender. The marrow cells were layered on Ficoll-Paque (Amersham Pharmaceutical Biotech, Piscataway, N.J., USA) and centrifuged $30 \mathrm{~min}$ at 1,900 RCF to concentrate nucleated cells at the interface. This fraction was collected, washed once with aMEM and cultured in $\alpha \mathrm{MEM}$ with $15 \%$ fetal calf serum and antibiotics. Adherent cells were replated just prior to confluence at $1 \times 10^{4} \mathrm{cells} / \mathrm{cm}^{2}$, and these first passage cultures were used for all experiments. At $24 \mathrm{~h}$, ascorbate-2-phosphate $(100 \mu \mathrm{g} / \mathrm{ml})$ was added to all cultures along with $10^{-7} M$ dexamethasone (Sigma, St. Louis, Mo., USA) or 100 ng/ml BMP-2 (Genetics Institute, Cambridge, Mass., USA) where appropriate. Cultures were usually harvested after 6 days for either RNA preparation or alkaline phosphatase assays.

\section{Isolation of Total RNA and Reverse Transcriptase Reactions}

Total RNA was isolated using TRI reagent (Molecular Research Center, Cincinnati, Ohio, USA), and stored at $-80^{\circ} \mathrm{C}$ [Diefenderfer et al., 2003b]. cDNA was prepared from $2 \mu \mathrm{g}$ total RNA using oligo(dT) and the First-Strand Synthesis System for RT-PCR (Invitrogen Life Tech., Carlsbad, Calif., USA).

\section{Analyses of mRNA Levels and Alkaline Phosphatase Activity}

cDNA samples were amplified using real-time PCR (Cepheid Smart Cycler, Sunnyvale, Calif., USA) and the LightCycler - FastStart DNA Master SYBG Green I kit (Roche Molecular Biochemicals, Mannheim, Germany). The protocol for real-time PCR and primer sets for alkaline phosphatase, BMP-2, Runx2, and noggin have been previously described [Diefenderfer et al., 2003a, b]. Primers for Id-1 were as described by Tamura et al. [1998]. Additional primer sets were as follows:

ALK-3:

forward primer $=5^{\prime}$ GCATAACTAATGGACATTGCT $3^{\prime}$ reverse primer $=5^{\prime}$ GCAGCTGGAGAAGATGATCATAGC 3'

ALK-6:

forward primer $=5^{\prime}$ GGCTCTGAGCTATGACAAGAGAG 3' reverse primer $=5^{\prime}$ CAAGAGCAAACTACAGACAGTCACAG 3'

Msx-2: forward primer $=5^{\prime}$ GCCATTTTCAGCTTTTCCAG 3' reverse primer $=5^{\prime}$ CCCTGAGGAAACACAAGACC $3^{\prime}$ FKHR:

forward primer: 5'AAGTTCTTGGTGGATGCTCAAT 3' reverse primer: 5' GGGCGAAATGTACTCCAGTTAT 3'

The primers for ALK-3, ALK-6, Msx-2, FKHR and noggin are suitable for analyzing both human and rat mRNAs. The alkaline phosphatase and BMP2 primers are designed for humans but not rat. The Runx 2 primers span exons 6 and 7 of human Runx2, which is a region downstream of the Runt domain that has not yet been sequenced in rat.

The amount of alkaline phosphatase mRNA was determined from real-time RT-PCR assays based on a standard plot obtained with cloned human alkaline phosphatase cDNA. Results from other real-time RT-PCR assays were converted to arbitrary units of mRNA 
Table 1. Alkaline phosphatase induction by BMP in human MSC

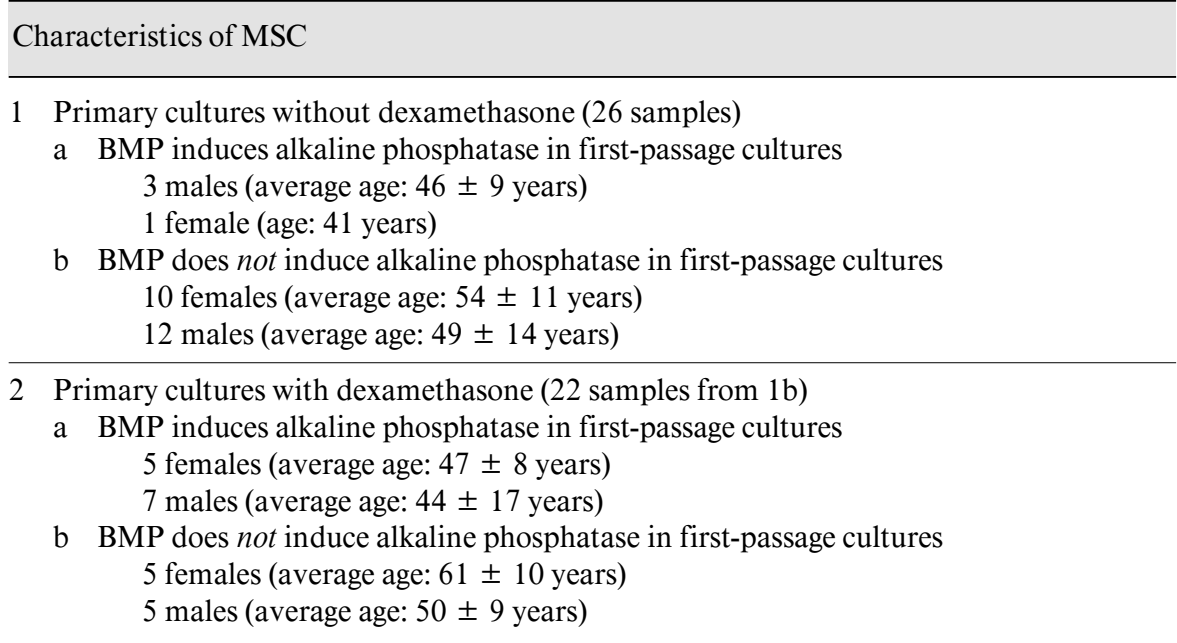

BMP response is defined as an alkaline phosphatase activity increase of $>50 \%$ above nontreated control for that sample. assuming a straight line, with a value for the slope of 3.5 (change in $\log$ concentration of mRNA/cycle), and the crossing point cycle number with no template as an estimate of y-intercept. The result, expressed as log concentration, was then converted to its antilog.

RNase protection assays were performed with an RPA III ${ }^{\mathrm{TM}} \mathrm{Kit}$ (Ambion, Austin, Tex., USA). Alkaline phosphatase enzyme activity was assayed as described previously [Rickard et al., 1994]. Statistical analyses for significant differences in enzyme activity and mRNA levels were performed with the SigmaStat t test program.

\section{Adenovirus Expression Vectors}

Plasmids containing constitutively active (CA) mutants of ALK-3 and ALK-6 receptors were kindly provided by Dr. Lee Niswander [Zou et al., 1997]. The coding sequences were isolated and cloned into adenoviral vectors as described by Hardy et al. [1997], using pAdLox plasmid shuttle vector and an adenovirus expressing Cre recombinase. Adenovirus expressing Msx-2 was a gift from Dr. Lillian Shum [Takahashi et al., 2001]. Adenovirus used for expression studies were purified by cesium chloride centrifugation before cell infection. MSC were infected with adenovirus twice, at either day 1 and day 3 after plating (ALK-containing virus) or day 1 and day 4 (Msx-2-containing virus), using a multiplicity of 25 virus particles/ cell at each time.

\section{Results}

We have expanded our studies of alkaline phosphatase levels in human MSC cultured with BMP-2 to include 26 patient samples. The samples were divided into primary culture either with or without $100 \mathrm{n} M$ dexamethasone, grown to confluence, and then replated in first passage for analysis of alkaline phosphatase induction at day 6 . Among the 26 samples, we identified 4 individuals whose
MSC in first passage cultures showed BMP-induced alkaline phosphatase at day 6 without prior exposure to dexamethasone (table 1, part 1a). The remaining 22 nonresponsive samples were almost equally split between male and female individuals (table 1, part 1b). As reported previously [Diefenderfer et al., 2003b], marrow cell samples that had been cultured with dexamethasone in primary culture showed an increased frequency of BMP-induced alkaline phosphatase after replating (table 1, part 2). Among the 22 samples characterized as BMP-nonresponsive in table 1 (part 1b) approximately half developed the ability to respond to BMP with increased alkaline phosphatase levels if treated with dexamethasone in primary culture. Overall, the Dex-pretreated responders appeared to have an average age somewhat lower than that of nonresponders, but the difference was not statistically significant. Among the samples from women patients, however, the average age of responders was significantly lower than the age of nonresponders ( 47 vs. 61 years; $p=0.04$ ). RNA was prepared from a subset of the samples and analyzed for alkaline phosphatase mRNA by real-time RT-PCR. The results confirmed that the inability of BMP to induce high alkaline phosphatase activity was paralleled by low levels of alkaline phosphatase mRNA.

Although the majority of our patient samples showed impaired alkaline phosphatase induction with BMP treatment, all tested samples showed BMP induction of noggin mRNA, which indicates that BMPs were capable of eliciting some transcriptional response. To examine the status of BMP receptors in MSC, we analyzed the expression 
of the BMP receptors ALK-3 and ALK- 6 both by conventional RT-PCR and RNase protection assays. ALK-3 is found in a wide variety of developing tissues, while ALK6 expression tends to be more restricted to skeletal tissues [Cheifetz, 1999]. As shown in figure 1, we detected ALK6 mRNA in both rat MSC and in human U20S cells. However, only ALK-3 but not ALK-6 mRNA was found in human MSC, and prior exposure to dexamethasone in primary culture did not alter these results.

It therefore seemed plausible that the impaired BMP response we observed in most human MSC was correlated with the absence of the BMP receptor ALK-6. To examine this hypothesis, we constructed adenoviral vectors containing CA ALK-3 and ALK-6 receptors, and infected them into both human and rat MSC. Cells infected with these viruses expressed high levels of the BMP receptors when the mRNA was analyzed by PCR (fig. 2a, b). Rat MSC overexpressing CA ALK-3 or CA ALK-6 showed levels of alkaline phosphatase activity that were markedly higher than those seen in rat MSC infected with control adenovirus and cultured with BMP-2; however, overexpressing the CA BMP receptors in human MSC had no effect on alkaline phosphatase expression (fig 2c). These results suggest that the lack of alkaline phosphatase regulation by BMPs is not due to absence of the ALK-6 receptor.

Although there is no evidence that BMP-induced signaling directly regulates alkaline phosphatase gene transcription, Hollnagel et al. [1999] showed that BMPs do directly regulate expression of the Id and Msx transcription factors implicated in morphogenesis and differentiation. It was therefore reasonable to postulate that BMP regulation of osteoblast genes occurs via transcriptional regulation of several other transcription factors that, in turn, regulate subsets of osteoblast-related genes. Because Msx-2 is a homeobox gene known to play critical roles in osteoblast differentiation and skeletal development [Dodig et al., 1999; Satokata et al., 2000], we measured levels of Msx-2 mRNA in human and rat MSC by real-time RTPCR. As expected, BMP increased Msx-2 expression in both rat and human MSC (fig. 3); however, while BMP caused a 2-fold increase in Msx-2 mRNA in rat cells, it produced a 10-fold increase in the human cells. We therefore asked whether overexpressing Msx-2 in BMP-treated rat or Dex-treated human MSC would alter alkaline phosphatase expression in these cells.

MSC were infected with adenovirus containing the wild-type Msx-2 gene at day 1 and 4 of first passage culture. Samples were harvested for RNA analyses at day 6 and for alkaline phosphatase enzyme assays at day 7. As

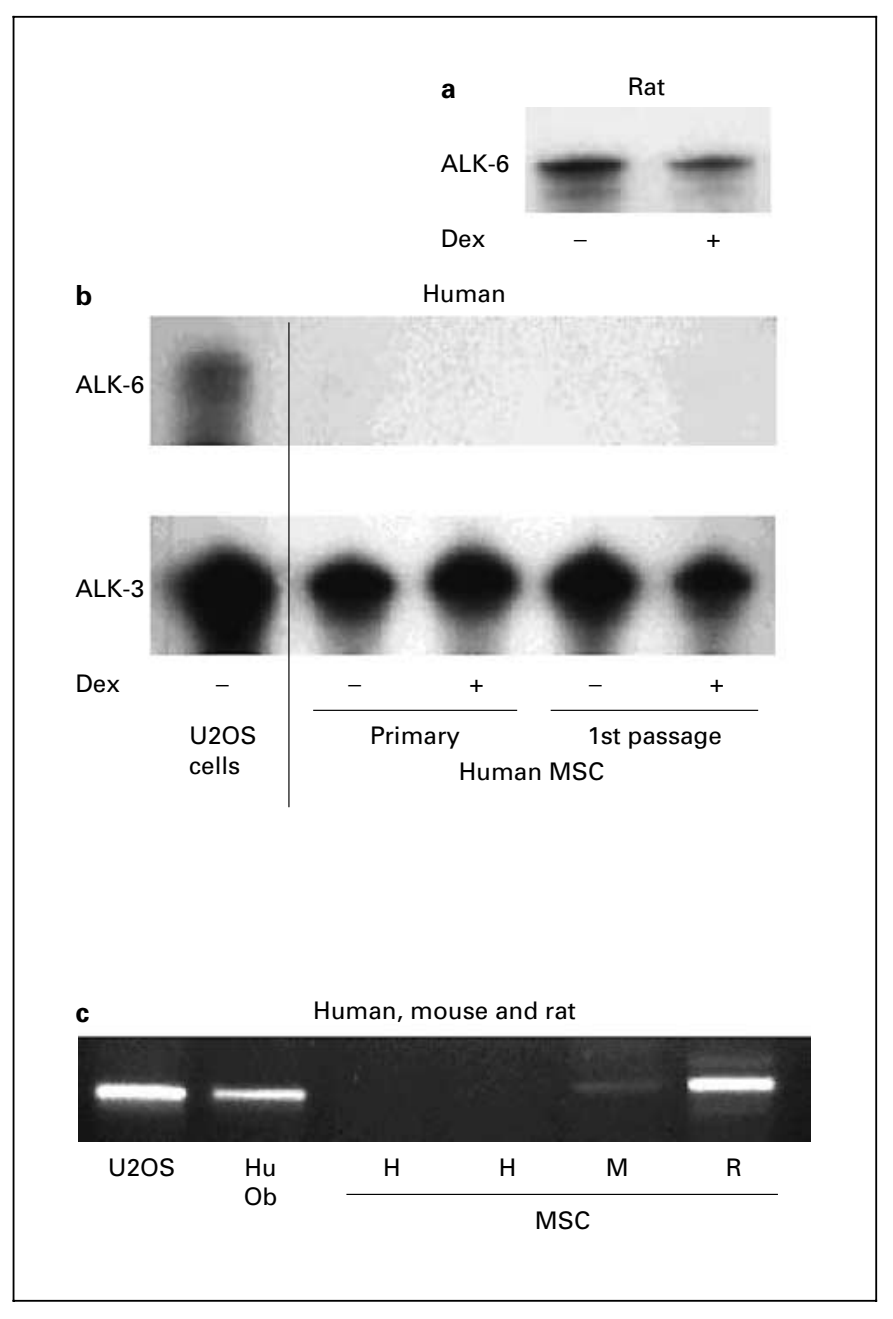

Fig. 1. Analyses of BMP receptor mRNAs. RNase protection assays for ALK-6 and ALK-3 from rat (a) and human (b) MSC, as well as from U-2 OS, a human osteosarcoma cell line obtained from ATCC (cell line HTB-96). c RT-PCR analysis of mRNAs from U-2 OS cells, first-passage human osteoblasts derived from trabecular bone $(\mathrm{Hu}$ $\mathrm{Ob})$, and MSC from human (H), mouse (M), and rat (R). While rat MSC and differentiated human osteoblasts expressed mRNA for ALK-6, human and mouse MSC did not. Human and rat MSC were from first-passage cells, while those from mouse were subcultured until third passage to diminish contamination from nonfibroblastic cells.

shown in figure 4a, levels of Msx-2 mRNA were greatly increased when MSC were infected with adenovirus containing the Msx gene. However, overexpressing Msx-2 did not significantly affect either alkaline phosphatase mRNA (fig. 4b) or alkaline phosphatase activity (fig. 4c). It therefore seems unlikely that the lack of BMP-induced alkaline phosphatase in human MSC is caused by the high levels of Msx-2 produced in BMP-treated human MSC. 


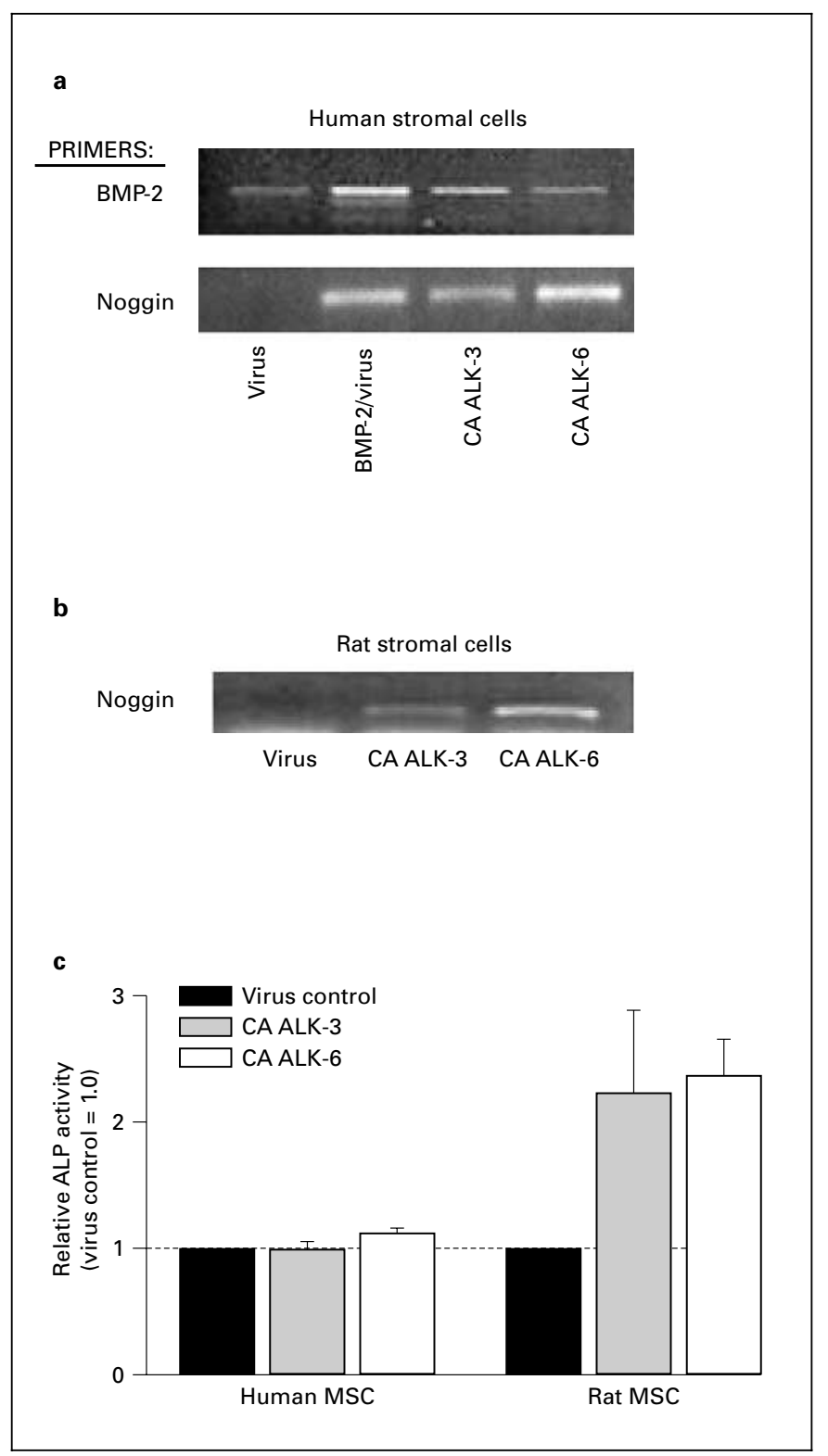

Fig. 2. Expression of CA BMP receptors in human and rat MSC. Cells were infected, at 1 and 3 days after plating, with adenoviruscontaining CA ALK-3 or ALK-6, and cultured until day 6. a RNA from human MSC contained elevated levels of both BMP-2 and noggin mRNA when cells had been either treated with BMP-2 + control virus, or infected with virus containing CA ALK-3 or ALK-6. The CA BMP receptors therefore increased transcription of these BMPresponsive genes. b RNA from rat MSC also showed a response to CA ALK-3 and ALK-6, as demonstrated by increases in noggin mRNA. c Rat MSC overexpressing CA BMP receptors responded with increased alkaline phosphatase (ALP) activity, but human MSC did not.

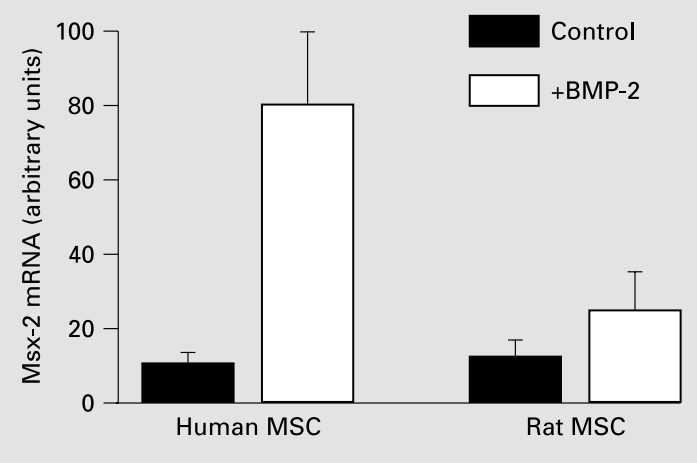

Fig. 3. BMP induction of Msx-2 expression. Levels of Msx-2 mRNA, measured by real-time PCR of cDNA, were increased in both rat and human MSC. However, human MSC showed a significantly greater stimulation of Msx-2 expression than rat MSC $(p=0.003)$.

The effects of BMP-2 on expression of several other transcription factors implicated in osteogenesis were also examined by real-time RT-PCR analyses of samples from human MSC. Levels of Id1, a negative regulator of myogenesis that promotes alternative differentiation pathways, were increased 2- to 3-fold in all BMP-treated human MSC. This result is consistent with previous reports that BMP increases Id expression in mouse osteoblast precursors and mouse embryonic stem cells [Ogata et al., 1993; Hollnagel et al., 1999]. Using primers that should detect all Runx2 mRNA isoforms, our analyses suggested that neither rat nor human MSC show a significant increase in total Runx 2 mRNA in response to BMP2. More surprising results were obtained when we analyzed expression of the forkhead transcription factor FKHR (FOXO1a). As shown in figure 5, BMP-treated human MSC showed almost twice as much FKHR mRNA as control. However, dexamethasone-treated human MSC expressed even greater amounts of FKHR mRNA, reaching levels significantly higher than either control or BMP-treated samples.

\section{Discussion}

The discovery that BMPs were growth and differentiation factors capable of inducing both ectopic bone formation and accelerated bone repair generated widespread interest in their potential as therapeutic agents that could promote fracture healing and implant osseointegration, 

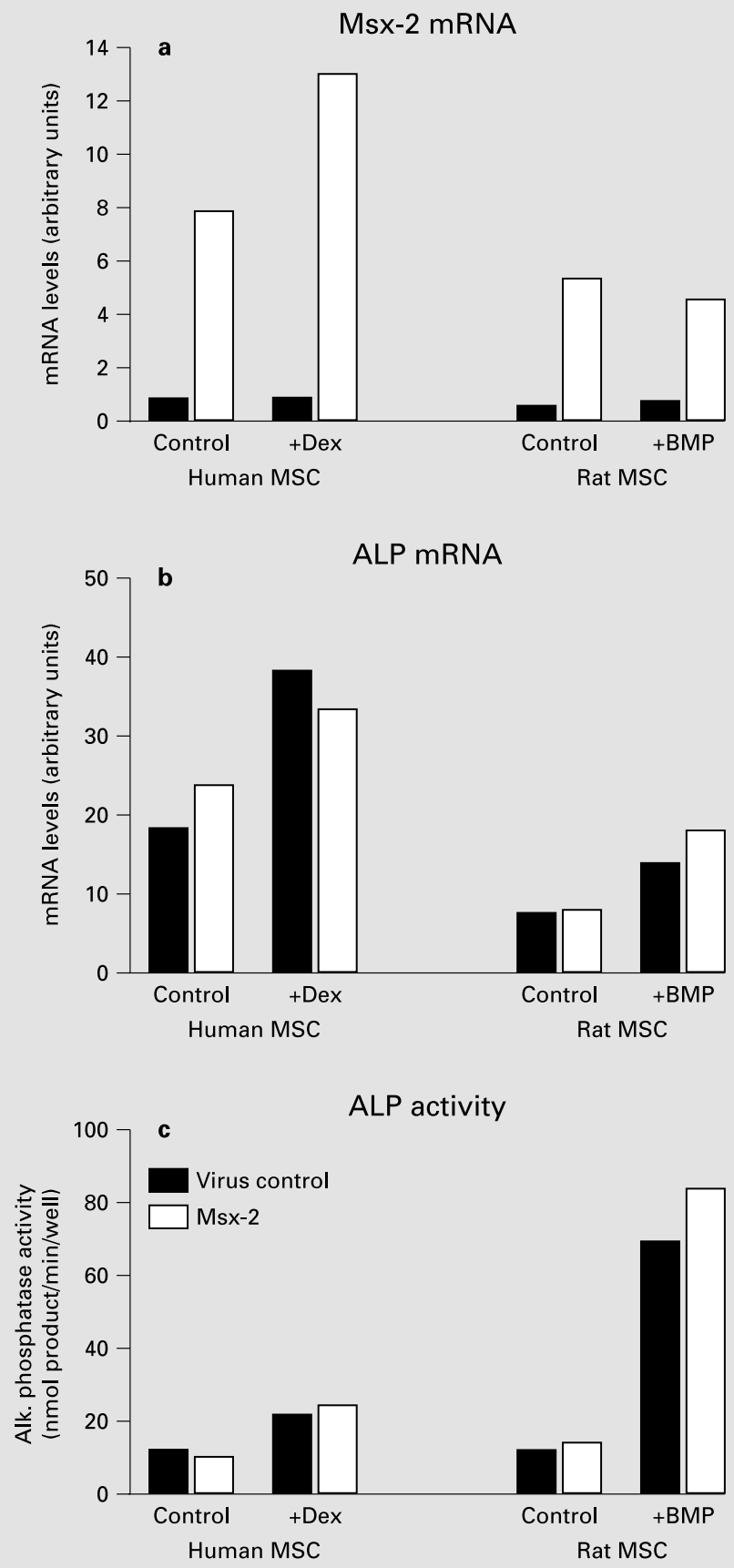

Fig. 4. Effects of overexpressing Msx-2 in human and rat MSC. a Both human and rat MSC have elevated levels of Msx-2 mRNA in response to infection with Msx-2 adenovirus. b Overexpression of Msx-2 has no effect on levels of alkaline phosphatase (ALP) mRNA in either human or rat MSC. c Alkaline phosphatase activity is unaltered when rat and human MSC overexpress Msx-2. Levels of mRNA, determined by real-time RT-PCR, are calculated as described in Materials and Methods.

BMP Effects on Marrow Stromal Cell

Osteogenesis

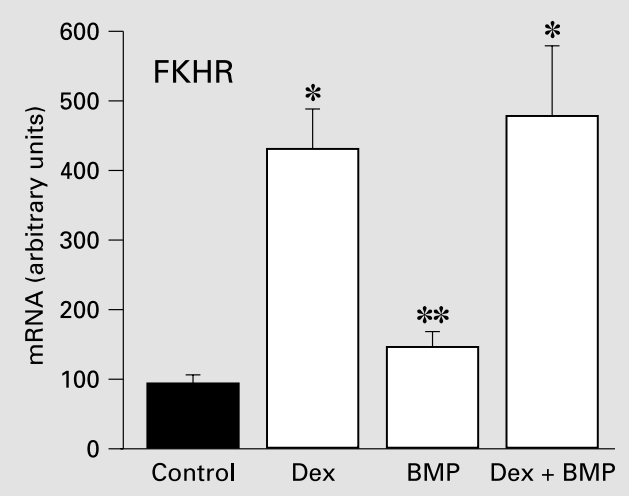

Fig. 5. Expression of the forkhead transcription factor FKHR in human MSC. Real-time RT-PCR analyses of FKHR mRNA indicated that human MSC respond to either $100 \mathrm{n} M$ dexamethasone (Dex) or $100 \mathrm{ng} / \mathrm{ml} \mathrm{BMP-2}$ with increased expression of FKHR. However, the effect of Dex is significantly greater than that of BMP2. Difference between Dex-treated or Dex+BMP and either control or BMP-treated is significant at ${ }^{*} \mathrm{p}<0.001$; difference between BMPtreated and control is significant at $* * p=0.002$.

and perhaps even counteract osteoporosis. This potential was reinforced by studies using several rodent models, which demonstrated that targets for BMP action include not only bone-derived osteoblasts and committed osteoprogenitor cells, but also multipotential mesenchymal stem cells [Katagiri et al., 1990; Scutt et al., 1992; Thies et al., 1992; Erlebacher et al., 1995; Mundy et al., 1995; Yamaguchi et al., 1996, 2000; Reddi, 2001]. Reports that BMPs could promote osteogenic commitment of MSC from rats and mice assumed increasing importance with the recognition that these cells are a major source of osteoblasts required in adult bone remodeling and repair. For this reason, efforts are ongoing to genetically engineer MSC overexpressing BMPs for implantation into bone repair sites [Lou et al., 1999; Franceschi et al., 2000; Cheng et al., 2001].

There have been more than a dozen reports of human clinical trials using recombinant BMPs for spinal fusions, healing long bone fractures, and repair of bony defects in the oral cavity. While most of these achieved some success in improving or accelerating bone formation, they required BMP levels markedly higher than expected from animal studies and showed significant patient variability in response to BMP treatment [Groeneveld and Burger, 2000; Lane, 2001; Govender et al., 2002]. Our studies were initiated to examine whether the clinical results

Cells Tissues Organs 2004;176:109-119 
might be associated with differences in the ability of human versus rodent MSC to undergo osteogenesis in response to BMPs. Initial results measuring alkaline phosphatase levels in MSC cultured in the presence of BMPs demonstrated that although rat MSC showed elevated alkaline phosphatase expression with either BMPs or dexamethasone, human MSC showed increased alkaline phosphatase with dexamethasone but not with BMP-2, BMP-4, or BMP-7 [Diefenderfer et al., 2003b]. Subsequent real-time RT-PCR studies demonstrated that, although alkaline phosphatase mRNA remained low in human MSC cultures treated with BMP-2 for as long as 2 weeks, several other genes including those coding for noggin, BMP-2, osteopontin, and bone sialoprotein were transcriptionally activated when human MSC were cultured with BMP-2, BMP-4, or BMP-7 [Diefenderfer et al., 2003a].

Because BMP was able to stimulate expression of some genes in human MSC, we examined the possibility that specificity in downstream actions of BMP signaling was related to differences in the use of BMP receptors. This hypothesis was triggered by the observation that human MSC did not produce mRNA for one of the type I BMP receptors. Although rat MSC and differentiated human osteoblasts express mRNA for ALK-6 (fig. 1a, c), human MSC lack this BMP receptor (fig. 1b, c). If human MSC were unable to increase alkaline phosphatase expression in response to BMPs due to lack of the ALK-6 receptor, overexpressing a CA form of this receptor should cause increased alkaline phosphatase levels. Although rat MSC infected with CA ALK-6 responded as expected, human MSC expressing CA ALK-6 did not show increased alkaline phosphatase activity (fig. 2). These results suggest that lack of BMP-induced alkaline phosphatase in human MSC is not caused by absence of ALK-6. Further support for this conclusion comes from our observations that mouse MSC expressed little ALK-6 mRNA (fig. 1c), although they undergo osteogenesis in response to BMPs. ST2, a mouse stromal cell line that shows BMP-induced increases in alkaline phosphatase, has previously been reported to lack the ALK-6 receptor [Otsuka et al., 1999].

Increased expression of alkaline phosphatase in BMPtreated rodent cells requires at least $12 \mathrm{~h}$ [Thies et al., 1992], which suggests that it is not a primary target for BMP-activated signaling. The relatively slow response of alkaline phosphatase is in contrast to the more rapid BMP response seen with genes known to be directly regulated by BMP-induced Smad signaling. For example, the transcription factors Id1 and Msx-2 are induced by BMP within 30 min [Hollnagel et al., 1999; López-Rovira et al.,
2002]. We examined the mRNA levels for these earlyresponse genes in human MSC, and found that both of them showed increased expression when the cells had been cultured in the presence of BMP-2 (fig. 3). The level of BMP induction of Id1 was comparable in human and rat MSC, but Msx-2 expression in response to BMP was significantly greater in human MSC than in rat MSC.

Msx-2 is a member of the homeobox family of transcription factors that usually functions as a transcriptional repressor. Mice lacking Msx-2 expression display defects in both intramembranous and endochondral bone formation [Satokata et al., 2000], and one noteworthy characteristic of Msx expression is its association with multipotential progenitor cells including osteoprogenitors [Liu et al., 1999]. Overexpression studies suggest that Msx-2 acts to stimulate proliferation and inhibit differentiation of osteoprogenitors [Dodig et al., 1999]. These characteristics prompted us to examine whether overexpression of Msx-2 in human MSC resulted in the inability of the cells to differentiate into osteoblasts producing high levels of alkaline phosphatase. While an attractive hypothesis, overexpressing Msx-2 in MSC failed to alter alkaline phosphatase activity (fig. 4).

Expression of one of the forkhead transcription factors, FKHR, was investigated because it has been reported to stimulate osteoblast alkaline phosphatase activity in mouse cells [Bois and Grosveld, 2003] and increase activity of an alkaline phosphatase promoter construct [Hatta et al., 2002]. There are over two dozen known members of the forkhead family, with FHKR falling within the FoxO subfamily. Forkhead proteins regulate a wide variety of cellular activities including cell cycle, apoptosis, insulin signaling, glucose metabolism, embryogenesis, and cell differentiation. Although most frequently studied as an effector of insulin-mediated metabolic changes, there is emerging evidence that FKHR(FoxO1a) is also involved in differentiation [Bois and Grosveld, 2003]. Little is known about factors regulating the expression of FoxO proteins; however, treatment of a chondrogenic cell line with dexamethasone or BMPs will induce expression of a forkhead protein in the FoxC subfamily [Nifuji et al., 2001]. Our studies show that the same is true for a member of the FoxO subfamily, FKHR. Because dexamethasone treatment yielded a 5-fold elevation of FKHR mRNA while BMP-induced levels were markedly lower (fig. 5), it is possible that FKHR expression in human MSC treated with BMPs is insufficient to activate alkaline phosphatase expression.

Another transcription factor that is a candidate for acting downstream of BMP signaling is Runx2 (Cbfa1). Our 
RT-PCR studies, with primers that amplify a region of Runx2 mRNA near the $3^{\prime}$ end of the coding region, have indicated that Runx 2 mRNA is expressed at comparable levels in control, BMP-treated, and dexamethasonetreated human MSC [Diefenderfer et al., 2003a]. Our primers, however, were designed for hybridization to mRNA common to all Runx2 isoforms, and recent evidence suggests there are at least 6 different isoforms of Runx 2 that are either splice variants or differ in transcription start sites [Xiao et al., 2003]. Multipotential and osteoprogenitor cell lines appear to express mainly the type I isoform of Runx 2 transcribed from the downstream promoter [Sudhakar et al., 2001], while mature osteoblasts also contain mRNA for a type II isoform transcribed from the far upstream promoter and induced by BMP [Banerjee et al., 2001; Sudhakar et al., 2001]. Furthermore, there is evidence for both translational control of Runx 2 isoforms [Sudhakar et al., 2001] and for kinasemediated activation of Runx2 [Franceschi and Xiao, 2003]. It is therefore plausible that differences in BMP response between rodent and human MSC may be associated with differences in BMP-induced changes in Runx2 that could not be detected by our PCR analyses.

Our studies with human MSCs isolated from the femoral cavity of over two dozen patients indicate that a high proportion of the samples do not show a full osteogenic response to BMPs in cell culture. In vivo, cells contribut- ing to fracture repair will presumably include not only multipotential MSC but also cells already committed to the osteoblast lineage and therefore capable of responding to BMPs with increased alkaline phosphatase expression. It is also reasonable to expect some glucocorticoid action on MSC in the vasculature, which may increase their BMP responsiveness. Very recent studies in our laboratory indicate that, when human MSC from the femoral cavity are shifted to culture conditions that alter intracellular kinase signaling pathways, they can respond to BMP-2 with increased expression of both alkaline phosphatase and osteopontin [Osyczka et al., 2003]. These results suggest that changes in extracellular signaling molecules may alter the response of MSC to BMPs. It should also be noted that, while we obtain the same results with MSC derived from either humerus or femur, we have not yet examined whether human MSC derived from other bone marrow sites will show similar characteristics. We also plan to test whether human MSC from pediatric patients will be as refractory to BMP-induced alkaline phosphatase as those from adult patients.

\section{Acknowledgments}

We gratefully acknowledge gifts of BMP from Wyeth/Genetics Institute, and adenovirus expressing Msx-2 from Dr. Lillian Shum at NIH. These studies were supported by NIH grant DE13962.

\section{References}

Abe, E., M. Yamamoto, Y. Taguchi, B. Lecka-Czernik, C.A. O'Brien, A.N. Economides, N. Stahl, R.L. Jilka, S.C. Manolagas (2000) Essential requirement of BMPs-2/4 for both osteoblast and osteoclast formation in murine bone marrow cultures from adult mice: Antagonism by noggin. J Bone Miner Res 15: 663-673.

Alliston, T., L. Choy, P. Ducy, G. Karsenty, R. Derynck (2001) TGF- $\beta$-induced repression of CBFA1 by Smad3 decreases cbfal and osteocalcin expression and inhibits osteoblast differentiation. EMBO J 20: 2254-2272.

Aubin, J.E. (1998) Bone stem cells. J Cell Biochem 30-31: 73-82.

Balk, M.L., J. Bray, C. Day, M. Epperly, J. Greenberger, C.H. Evans, C. Niyibizi (1997) Effect of rhBMP-2 on the osteogenic potential of bone marrow stromal cells from an osteogenesis imperfecta mouse (oim). Bone 21: 7-15.

Banerjee, C., A. Javed, J.Y. Choi, J. Green, V. Rosen, A.J. van Wijnen, J.L. Stein, J.B. Lian, G.S Stein (2001) Differential regulation of the two principal Runx $2 / \mathrm{Cbfa} 1 \mathrm{~N}$-terminal isoforms in response to bone morphogenetic protein-2 during development of the osteoblast phenotype. Endocrinology 142: 4026-4039.
Bois, P., G. Grosveld (2003) FKHR (FOXO1a) is required for myotube fusion on primary mouse myoblasts. EMBO J 22: 1147-1157.

Cheifetz, S. (1999) BMP receptors in limb and tooth development. Crit Rev Oral Biol Med 10: 182-198.

Cheng, S.L., J. Lou, N.M. Wright, C.F. Lai, L.V. Avioli, K.D. Riew (2001) In vitro and in vivo induction of bone formation using a recombinant adenoviral vector carrying the human BMP-2 gene. Calcif Tissue Int 68: 87-94.

Cook, S.D., G.C. Baffes, M.W. Wolfe, T. Kuber Sampath, D.C. Rueger, T.S. Whitecloud (1994) The effect of recombinant human osteogenic protein- 1 on healing of large segmental bone defects. J Bone Joint Surg Am 6A: 827-838.

Dennis, J.E., A. Merriam, A. Awadallah, J.U. Yoo, B. Johnstone, A.I. Caplan (1999) A quadripotential mesenchymal progenitor cell isolated from the marrow of an adult mouse. $\mathrm{J}$ Bone Miner Res 14: 700-709.

Diefenderfer, D.L., A.M. Osyczka, J.P. Garino, P.S. Leboy (2003a) Regulation of BMP-induced transcription in cultured human bone marrow stromal cells. J Bone Joint Surg Am 85A (suppl 2): 19-28.
Diefenderfer, D.L., A.M. Osyczka, G.C. Reilly, P.S. Leboy (2003b) BMP responsiveness in human mesenchymal stem cells. Connect Tissue Res 44: 305-311.

Dodig, M., T. Tadic, M.S. Kronenberg, S. Dacic, Y.H. Liu, R. Maxson, D.W. Rowe, A.C. Lichtler (1999) Ectopic Msx2 overexpression inhibits and $M s \times 2$ antisense stimulates calvarial osteoblast differentiation. Dev Biol 209: 298307.

Erices, A., P. Conget, J.J. Minguell (2000) Mesenchymal progenitor cells in human umbilical cord blood. Br J Haematol 109: 235-242.

Erickson, G.R., J.M. Gimble, D.M. Franklin, H.E. Rice, H. Awad, F. Guilak (2002) Chondrogenic potential of adipose tissue-derived stromal cells in vitro and in vivo. Biochem Biophys Res Commun 290: 763-769.

Erlebacher, A., E.H. Filvaroff, S.E. Gitelman, R. Derynck (1995) Towards a molecular understanding of skeletal development. Cell 80: 371 278.

Franceschi, R.T., D. Wang, P.H. Krebsbach, R.B. Rutherford (2000) Gene therapy for bone formation: In vitro and in vivo osteogenic activity of an adenovirus expressing BMP7. J Cell Biochem 78: 476-486. 
Franceschi, R.T., G.Z. Xiao (2003) Regulation of the osteoblast-specific transcription factor Runx2: Responsiveness to multiple signal transduction pathways. J Cell Biochem 88 . 446-454.

Friedenstein, A.J., R.K. Chailakhyan, U.V. Gerasimov (1987) Bone marrow osteogenic stem cells: In vitro cultivation and transplantation in diffusion chambers. Cell Tissue Kinet 20: $263-$ 272.

Gerhart, T.N., C.A. Kirker-Head, M.J. Kriz, M.E. Holtrop, G.E. Hennig, J. Hipp, S.H. Schelling, E. Wang (1993) Healing segmental femoral defects in sheep using recombinant human bone morphogenetic protein. Clin Orthop 293: 317 326.

Govender, S., C. Csimma, H.K. Genant, A. Valentin-Opran; BESTT Study Group (2002) Recombinant human bone morphogenetic protein-2 for treatment of open tibial fractures - A prospective, controlled, randomized study of four hundred and fifty patients. J Bone Joint Surg Am 84A: 2123-2134.

Grigoriadis, A.E., J.N. Heersche, J.E. Aubin (1988) Differentiation of muscle, fat, cartilage and bone from progenitor cells present in a bonederived clonal cell population: Effect of dexamethasone. J Cell Biol 106: 2139-2151.

Groeneveld, E.H., E.H. Burger (2000) Bone morphogenetic proteins in human bone regeneration. Eur J Endocrinol 142: 9-21.

Gutierrez, S., A. Javed, D.K. Tennant, M. Van Rees, M. Montecino, G.S. Stein, J.L. Stein, J.B. Lian (2002) CCAAT/enhancer-binding proteins (C/EBP) $\beta$ and $\delta$ activate osteocalcin gene transcription and synergize with Runx2 at the C/EBP element to regulate bone-specific expression. J Biol Chem 277: 1316-1323.

Hanada, K., J.E. Dennis, A.I. Caplan (1997) Stimulatory effects of basic fibroblast growth factor and bone morphogenetic protein-2 on osteogenic differentiation of rat bone marrow-derived mesenchymal stem cells. J Bone Miner Res 12: 1606-1614.

Hanai, J., L.F. Chen, T. Kanno, N. Ohtani-Fujita W.Y. Kim, W.H. Guo, T. Imamura, Y. Ishidou, M. Fukuchi, M.J. Shi, J. Stavnezer, M. Kawabata, K. Miyazono, Y. Ito (1999) Interaction and functional cooperation of PEBP2/ CBF with Smads - Synergistic induction of the immunoglobulin germline $\mathrm{C} \alpha$ promoter. J Biol Chem 274: 31577-31582.

Hardy, S., M. Kitamura, T. Harris-Stansil, Y. Dai, M. Phipps (1997) Construction of adenovirus vectors through Cre-lox recombination. J Virol 71: 1842-1849.

Hatta, M., H. Daitoku, H. Matsuzaki, Y. Deyama, Y. Yoshimura, K. Suzuki, A. Matsumoto, A. Fukamizu (2002) Regulation of alkaline phosphatase promoter activity by forkhead transcription factor FKHR. Int J Mol Med 9: 147 152.

Heckman, J.D., W. Ehler, B.P. Brooks, T.B. Aufdemorte, C.H. Lohmann, T. Morgan, B.D. Boyan (1999) Bone morphogenetic protein but not transforming growth factor- $\beta$ enhances bone formation in canine diaphyseal nonunions implanted with a biodegradable composite polymer. J Bone J Surg Am 81A: 1717-1729.
Hollnagel, A., V. Oehlmann, J. Heymer, U. Rüther, A. Nordheim (1999) Id genes are direct targets of bone morphogenetic protein induction in embryonic stem cells. J Biol Chem 274: 1983819845 .

Javed, A., G.L. Barnes, B.O. Jasanya, J.L. Stein, L. Gerstenfeld, J.B. Lian, G.S. Stein (2001) Runt homology domain transcription factors (Runx, Cbfa, and AML) mediate repression of the bone sialoprotein promoter: Evidence for promoter context-dependent activity of Cbfa proteins. Mol Cell Biol 21: 2891-2905.

Katagiri, T., A. Yamaguchi, T. Ikeda, S. Yoshiki, J.M. Wozney, V. Rosen, E.A. Wang, H. Tanaka, S. Omura, T. Suda (1990) The non-osteogenic mouse pluripotent cell line, C3H10T1/2, is induced to differentiate into osteoblastic cells by recombinant human bone morphogenetic protein-2. Biochem Biophys Res Commun 172: 295-299.

Kiyoshima, T., M. Yamauchi, C. Wong, A. Jheon, B. Ganss, J. Sodek (2002) An L1 element disrupts human bone sialoprotein promoter: Lack of tissue-specific regulation by distalless 5 (Dlx5) and runt homeodomain protein2 (Runx2)/core binding factor a1 (Cbfa1) elements. Gene 299: 205-217.

Komori, T., H. Yagi, S. Nomura, A. Yamaguchi, K. Sasaki, K. Deguchi, Y. Shimizu, R.T. Bronson, Y.H. Gao, M. Inada, M. Sato, R. Okamoto, Y. Kitamura, S. Yoshiki, T. Kishimoto (1997) Targeted disruption of $\mathrm{Cbfal}$ results in a complete lack of bone formation owing to maturational arrest of osteoblasts. Cell 89: 755-764.

Kopen, G.C., D.J. Prockop, D.G. Phinney (1999) Marrow stromal cells migrate throughout forebrain and cerebellum, and they differentiate into astrocytes after injection into neonatal mouse brains. Proc Natl Acad Sci USA 96: 10711-10716.

Kuznetsov, S.A., M.H. Mankani, S. Gronthos, K. Satomura, P. Bianco, P.G. Robey (2001) Circulating skeletal stem cells. J Cell Biol 153:11331139.

Lane, J.M. (2001) BMPs: Why are they not in everyday use? J Bone Joint Surg Am 83A: S161-S163.

Latzinik, N.V., A.G. Grosheva, A.N. Narovlyanskii, R.G. Pavlenko, A.J. Friedenstein (1987) Clonal nature of fibroblast colonies formed by bone marrow stromal cells in culture. Bull Exp Biol Med 103: 356-358.

Leboy, P.S., G. Grasso-Knight, M. D’Angelo, S.W. Volk, J.B. Lian, H. Drissi, G.S. Stein, S.L. Adams (2001) Smad-Runx interactions during chondrocyte maturation. J Bone Joint Surg Am 83A: S15-S22.

Lee, K.S., H.J. Kim, Q.L. Li, X.Z. Chi, C. Ueta, T. Komori, J.M. Wozney, E.G. Kim, J.Y. Choi, H.M. Ryoo, S.C. Bae (2000) Runx2 is a common target of transforming growth factor $\beta 1$ and bone morphogenetic protein 2 , and cooperation between Runx 2 and Smad5 induces osteoblast-specific gene expression in the pluripotent mesenchymal precursor cell line $\mathrm{C} 2 \mathrm{C} 12$. Mol Cell Biol 20: 8783-8792.
Liu, Y.H., Z.Q. Tang, R.K. Kundu, L.Y. Wu, W. Luo, D.H. Zhu, F. Sangiorgi, M.L. Snead, R.E. Maxson, Jr. (1999) Msx2 gene dosage influences the number of proliferative osteogenic cells in growth centers of the developing murine skull: A possible mechanism for $M S X 2$ mediated craniosynostosis in humans. Dev Biol 205: 260-274.

López-Rovira, T., E. Chalaux, J. Massagué, J.L. Rosa, F. Ventura (2002) Direct binding of Smad1 and Smad4 to two distinct motifs mediates bone morphogenetic protein-specific transcriptional activation of Id 1 gene. J Biol Chem 277: 3176-3185.

Lou, J.R., Y.Z. Tu, F.J. Ludwig, J.F. Zhang, P.R. Manske (1999) Effect of bone morphogenetic protein-12 gene transfer on mesenchymal progenitor cells. Clin Orthop 369: 333-339.

Mardon, H.J. J. Bee, K. von der Mark, M.E. Owen (1987) Development of osteogenic tissue in diffusion chambers from early precursor cells in bone marrow of adult rats. Cell Tissue Res 250: 157-165.

Massagué, J., D. Wotton (2000) Transcriptional control by the TGF- $\beta /$ Smad signaling system. EMBO J 19: 1745-1754.

McLarren, K.W., R. Lo, D. Grbavec, K. Thirunavukkarasu, G. Karsenty, S. Stifani (2000) The mammalian basic helix loop helix protein HES- 1 binds to and modulates the transactivating function of the Runt-related factor Cbfa1. J Biol Chem 275: 530-538.

Miyazono, K., K. Kusanagi, H. Inoue (2001) Divergence and convergence of TGF- $\beta /$ BMP signaling. J Cell Physiol 187: 265-276.

Moustakas, A.C. H. Heldin (2002) From mono- to oligo-Smads: The heart of the matter in TGF- $\beta$ signal transduction. Genes Dev 16: 18671871.

Mundlos, S., F. Otto, C. Mundlos, J.B. Mulliken, A.S. Aylsworth, S. Albright, D. Lindhout, W.G. Cole, W. Henn, J.H.M. Knoll, M.J. Owen, R. Mertelsmann, B.U. Zabel, B.R. Olsen (1997) Mutations involving the transcription factor CBFA1 cause cleidocranial dysplasia. Cell 89 : 773-779.

Mundy, G.R., B.F. Boyce, D.E. Hughes, K.L. Wright, L.F. Bonewald, S. Dallas, S. Harris, N. Ghosh-Choudhury, D. Chen, C. Dunstan, E. Izbicka, T. Yoneda (1995) The effects of cytokines and growth factors on osteoblastic cells. Bone 17: 71S-75S.

Muraglia, A., R. Cancedda, R. Quarto (2000) Clonal mesenchymal progenitors from human bone marrow differentiate in vitro according to a hierarchical model. J Cell Sci 113: 1161-1166.

Nakashima, K., X. Zhou, G. Kunkel, Z.P. Zhang, J.M. Deng, R.R. Behringer, B. De Crombrugghe (2002) The novel zinc finger-containing transcription factor Osterix is required for osteoblast differentiation and bone formation. Cell 108: 17-29.

Nifuji, A., N. Miura, N. Kato, O. Kellermann, M. Noda (2001) Bone morphogenetic protein regulation of forkhead/winged helix transcription factor Foxc2 (Mfh1) in a murine mesodermal cell line $\mathrm{C} 1$ and in skeletal precursor cells. J Bone Miner Res 16: 1765-1771. 
Ogata, T., J.M. Wozney, R. Benezra, M. Noda (1993) Bone morphogenetic protein 2 transiently enhances expression of a gene, Id (inhibitor of differentiation), encoding a helix-loophelix molecule in osteoblast-like cells. Proc Natl Acad Sci USA 90: 9219-9222.

Osyczka, A.M., G.C. Reilly, G.A. Bhargave, E.B. Golden, P.S. Leboy (2003) BMP regulation of human marrow stromal cell osteogenesis is promoted by decreased growth factor signaling and activation of the insulin/IGF-1 pathway. Submitted.

Otsuka, E., A. Yamaguchi, S. Hirose, H. Hagiwara (1999) Characterization of osteoblastic differentiation of stromal cell line ST2 that is induced by ascorbic acid. Am J Physiol 277: C132-138.

Otto, F., A.P. Thornell, T. Crompton, A. Denzel K.C. Gilmour, I.R. Rosewell, G.W.H. Stamp, R.S.P. Beddington, S. Mundlos, B.R. Olsen, P.B. Selby, M.J. Owen (1997) Cbfal, a candidate gene for cleidocranial dysplasia syndrome, is essential for osteoblast differentiation and bone development. Cell 89: 765-771.

Owen, M.E., J. Cave, C.J. Joyner (1987) Clonal analysis in vitro of osteogenic differentiation of marrow stromal CFU-F. J Cell Sci 87: 731738.

Owen, T.A., R. Bortell, S.A. Yocum, S.L. Smock, M. Zhang, C. Abate, V. Shalhoub, N. Aronin, K.L. Wright, A.J. van Wijnen, J.L. Stein, T Curran, J.B. Lian, G.S. Stein (1990) Coordinate occupancy of AP-1 sites in the vitamin Dresponsive and CCAAT box elements by fosjun in the osteocalcin gene: Model for phenotype suppression of transcription. Proc Natl Acad Sci USA 87: 9990-9994.

Reddi, A.H. (1998) Role of morphogenetic proteins in skeletal tissue engineering and regeneration. Nat Biotechnol 16: 247-252.

Reddi, A.H. (2001) Bone morphogenetic proteins: From basic science to clinical applications. J Bone Joint Surg Am 83A: S1-S6.
Rickard, D.J., T.A. Sullivan, B.J. Shenker, P.S. Leboy, I. Kazhdan (1994) Induction of rapid osteoblast differentiation in rat bone marrow stromal cell cultures by dexamethasone and BMP-2. Dev Biol 161: 218-228.

Ripamonti, U., B. Van den Heever, T.K. Sampath, M.M. Tucker, D.C. Rueger, A.H. Reddi (1996) Complete regeneration of bone in the baboon by recombinant human osteogenic protein-1 (hOP-1, bone morphogenetic protein-7). Growth Factors 13: 273-289.

Romanov, Y.A., V.A. Svintsitskaya, V.N. Smirnov (2003) Searching for alternative sources of postnatal human mesenchymal stem cells: Candidate MSC-like cells from umbilical cord. Stem Cells 21: 105-110.

Satokata, I., L. Ma, H. Ohshima, M. Bei, I. Woo, K. Nishizawa, T. Maeda, Y. Takano, C. Uchiyama, S. Heaney, H. Peters, Z.Q. Tang, R. Maxson, R. Maas (2000) Msx2 deficiency in mice causes pleiotropic defects in bone growth and ectodermal organ formation. Nat Genet 24: 391-395.

Scutt, A.M., H. Mayer, E. Wingender (1992) New perspectives in the differentiation of boneforming cells. Biofactors 4: 1-13.

Sen, A., Y.R. Lea-Currie, D. Sujkowska, D.M. Franklin, W.O. Wilkison, Y.D.C. Halvorsen, J.M. Gimble (2001) Adipogenic potential of human adipose derived stromal cells from multiple donors is heterogeneous. $\mathrm{J}$ Cell Biochem 81: 312-319.

Sudhakar, S., Y. Li, M.S. Katz, N. Elango (2001) Translational regulation is a control point in Runx2/Cbfa1 gene expression. Biochem Biophys Res Commun 289: 616-622.

Takahashi, K., G.H. Nuckolls, I. Takahashi, K. Nonaka, M. Nagata, T. Ikura, H.C. Slavkin, L. Shum (2001) Msx2 is a repressor of chondrogenic differentiation in migratory cranial neural crest cells. Dev Dyn 222: 252-262.

Tamura, Y., M. Sugimoto, K. Ohnishi, T. Sakai, E. Hara (1998) Differential activity of a variant form of the human Id-1 protein generated by alternative splicing. FEBS Lett 436: 169-173.
Thies, R.S., M. Bauduy, B.A. Ashton, L. Kurtzberg, J.M. Wozney, V. Rosen (1992) Recombinant human bone morphogenetic protein-2 induces osteoblastic differentiation in W-20-17 stromal cells. Endocrinology 130: 1318-1324.

Urist, M.R. (1965) Bone formation by autoinduction. Science 150: 893-899.

Wozney, J.M., V. Rosen (1998) Bone morphogenetic protein and bone morphogenetic protein gene family in bone formation and repair. Clin Orthop 346: 26-37.

Xiao, Z.S., S.G. Liu, T.K. Hinson, L.D. Quarles (2001) Characterization of the upstream mouse Cbfa1/Runx2 promoter. J Cell Biochem 82 647-659.

Xiao, Z.S., L.G. Simpson, L.D. Quarles (2003) IRES-dependent translational control of Cbfal/Runx 2 expression. J Cell Biochem 88 . 493-505.

Yamaguchi, A., T. Ishizuya, N. Kintou, Y. Wada, T. Katagiri, J.M. Wozney, V. Rosen, S. Yoshiki (1996) Effects of BMP-2, BMP-4, and BMP-6 on osteoblastic differentiation of bone marrowderived stromal cell lines, ST2 and MC3T3G2/PA6. Biochem Biophys Res Commun 220. 366-371.

Yamaguchi, A., T. Komori, T. Suda (2000) Regulation of osteoblast differentiation mediated by bone morphogenetic proteins, hedgehogs, and Cbfa1. Endocr Rev 21: 393-411.

Yang, X.L., X.H. Ji, X.M. Shi, X. Cao (2000) Smad1 domains interacting with hoxc-8 induce osteoblast differentiation. J Biol Chem 275. 1065-1072.

Zambotti, A., H. Makhluf, J.H. Shen, P. Ducy (2002) Characterization of an osteoblast-specific enhancer element in the CBFA1 gene. $\mathrm{J}$ Biol Chem 277: 41497-41506.

Zou, H.Y., R. Wieser, J. Massagué, L. Niswander (1997) Distinct roles of type I BMP receptors in the formation and differentiation of cartilage. Genes Dev 11: 2191-2203. 